\title{
Ubiquitous Computing in Education: A SWOT Analysis by Students and Teachers
}

\author{
Edgar Napoleon Asiimwe \\ Technology-Mediated Knowledge \\ Processes (TKP) Research School, \\ Dalarna University, Sweden \\ ena@du.se
}

\author{
Sana Zubair Khan \\ Technology-Mediated Knowledge \\ Processes (TKP) Research School, \\ Dalarna University, Sweden \\ ksanazubair@yahoo.com
}

\begin{abstract}
Learning from anywhere anytime is a contemporary phenomenon in the field of education that is thought to be flexible, time and cost saving. The phenomenon is evident in the way computer technology mediates knowledge processes among learners. Computer technology is however, in some instances, faulted. There are studies that highlight drawbacks of computer technology use in learning. In this study we aimed at conducting a SWOT analysis on ubiquitous computing and computer-mediated social interaction and their affect on education. Students and teachers were interviewed on the mentioned concepts using focus group interviews. Our contribution in this study is, identifying what teachers and students perceive to be the strength, weaknesses, opportunities and threats of ubiquitous computing and computer-mediated social interaction in education. We also relate the findings with literature and present a common understanding on the SWOT of these concepts.
\end{abstract}

Results show positive perceptions. Respondents revealed that ubiquitous computing and computer-mediated social interaction are important in their education due to advantages such as flexibility, efficiency in terms of cost and time, ability to acquire computer skills. Nevertheless disadvantages where also mentioned for example health effects, privacy and security issues, noise in the learning environment, to mention but a few. This paper gives suggestions on how to overcome threats mentioned.

Keywords: Ubiquitous Computing, Education, SWOT, Computer-mediated social interaction

\section{INTRODUCTION}

The term "ubiquitous computing" was first coined by Mark Weiser of Xerox PARC in 1988 who wrote, "The most profound technologies are those that disappear. They weave themselves into the fabric of everyday life until they are indistinguishable from it" (Wesier, 1991). Weiser's visionary reflections of such technologies and those of others were later believed to have transformed the way we interact and go about our daily lives. Practically, today we live surrounded by "ubiquitous" technology which is "invisible" to us. Like Weiser, a similar dream was envisioned by Turing, the father of Artificial Intelligence (AI) when he noted that: "What I would very much like to do is to educate a computer, partly by direct training, partly by letting it find out things for itself. We don't know how to do this yet, but I believe that it will be achieved in the very near future" (Feigenbaum, 1996 p.102). What is evident today is that we do not find out "things" by ourselves but the computers do that for us. Our intellect is influenced by technology which makes our operations ubiquitous.

The word ubiquitous literally means "existing or being everywhere at the same time", implying something that is constantly encountered, and widespread. Ubiquitous computing is technology that is pervasive and due to the pervasiveness, it is sometimes referred to as "pervasive computing". The pervasiveness of these technologies in our everyday environment 
tends to make us use it without thinking about it. Instead, we focus on the task at hand, making the technology invisible while still using it. Ubiquitous technology is often mobile, wireless, and networked, making its users more connected to the world around them and the people in it.

Computer-mediated social interaction is all kinds of social interaction communication using either a tool or technology e.g. Facebook, Skype, mobile phones, adhoc networks, etc. Both ubiquitous computing and computer-mediated social interaction are playing a role in the education sector today by modernizing the learning environments.

From ubiquitous computing as a concept, the mobile and wireless technologies have paved way to the concept of ubiquitous learning or u-learning. In definition, u-learning it can be said, has evolved from the influence of portability and immediate communication properties of mobile devices on the learning processes in interacting with peers, accessing resources and transferring data (Huang, et al., 2010). Mobile devices and wireless Internet technology enable learners to learn by a variety of digital resources from anywhere in the world at anytime (Hsieh, et al., 2011). This makes learning accessible, easy and more interesting.

Students are self-directed in a u-learning environment (Hsieh et al., 2011) and hence it could be said that u-learning facilitates a student centred learning environment. When students are situated in a u-learning environment, they can utilize information provided both by the real world and the Internet to solve problems in a timely manner (Chiou, et al., 2010). Students can also interact with experts, instructors, or learning peers and all students' learning activities can be recorded for later review and evaluation (Hsieh et al., 2011). The u-learning environment can host learning activities which are student-centered, knowledge-centered, assessment-centered, and community-centered (Hwang, et al., 2010). Also, collaborative networks can be created such as virtual laboratories which enable individuals and groups to work together (Camarinha-Matos \& Anesh, 2005). In ubiquitous learning, ubiquitous computing occurs all around the learner, whether or not they are aware of it (Liu \& Chu, 2010). Liu, et al. (2009) states the characteristics of u-learning as permanency, accessibility, immediacy, interactivity, situation, calmness, adaptability, seamlessness, and immersion. Therefore u-learning is a cornerstone for mobile learning - learning that uses mobile computing technologies to enhance learning, these technologies can be blended together to engage and motivate learners anytime, anywhere. This type of learning has more advantages compared to other means of learning, including flexibility, mobility, convenience, low cost, and user friendliness.

Like the u-learning environment, computer mediated social interaction also puts the user at the center of attention as an active player and social networks and Web 2.0 tools give students a more active role in their own education (Hwang et al., 2010). This notion derives from the content driven philosophy of Web 2.0, in which content is the main driver of new media applications. Whereas collaboration and social interaction are the driving forces behind opinions (e.g. through blogs, online discussion forums), knowledge (e.g., through wikis) or the sharing of digital artifacts (e.g. presentations, photos, audio, and video files) (Martin et al., 2011), these processes lead to the emergence of virtual communities that enable social networking. Today social interaction is what derives service personalization, content creation, and knowledge acquisition (Ibid, 2011), and social interaction itself is driven by ubiquitous technologies and computing. 
The immense presence of u-computing technologies in the world today, that led to the concept of u-learning through mobile and portable technologies is an insight into how ubiquitous computing has taken over our lives with or without us being aware of it, and learning has moved from the classroom and transformed the world into a classroom where these technologies are our medium to learning, and we have become our own teachers. Having said that, u-computing is bringing formal learning and informal learning closer and closer so that the boundaries are beginning to blend and merge. Teachers and students both have been affected by this transition as changing technologies bring changed environments, leading to new ways of approaching education and learning.

In this study we sought to address the question: What teachers and students perceive to be the strengths, weaknesses, opportunities and threats of ubiquitous computing and computermediated social interaction in education? Once the perceptions were identified using SWOT, we aimed at suggesting ways of overcoming threats and leveraging opportunities with reflections on contemporary literature. The rest of this paper presents the method that was used for this study, results, a reflection on results (discussion) and conclusive remarks.

\section{METHOD}

This study is qualitative and takes a deductive approach. Focus group interviews were chosen as the method for data collection. Respondents were grouped into two categories, that is, teachers and students. The teachers' group included five (5) teachers from Örebro University Informatics Department. The students' group on the other hand included eight students (8); two (2) from Uganda, one (1) from USA, one (1) from Spain, one (1) from France and the rest; three (3) from Turkey. Three out of the eight students participated online via Adobe Connect. The participants were selected on the criteria that they had experienced u-learning, other electronic and non-electronic learning environments.

The motivation for choosing focus group discussions as a method was to enable respondents have a shared forum to agree on their views regarding the questions presented to them. This approach provides information about a range of ideas and feelings that individuals have about certain issues, as well as highlighting the differences in perspective between groups of individuals (Rabiee, 2004). While each interview session took 60 to 90 minutes, both groups were interviewed separately on different days. The issues discussed were summarized by the moderators and agreed upon by the respondents at the end of each session. The moderators were (we) - the researchers.

The SWOT (Strength, Weaknesses, Threats and Opportunities) model was used to present questions on surveyed concepts in order to evaluate the Strengths, Weaknesses, Opportunities, and Threats of ubiquitous computing and computer-mediated social interaction. These questions were presented as listed below:

1. What do you perceive to be the:

a. Strengths of ubiquitous computing and computer-mediated social interaction?

b. Weaknesses of ubiquitous computing and computer-mediated social interaction?

c. Opportunities of ubiquitous computing and computer-mediated social interaction?

d. Threats of ubiquitous computing and computer-mediated social interaction?

2. What suggestions would you give to:

a. Overcome the mentioned threats and weaknesses?

b. Leverage the mentioned strengths and opportunities? 
The study also used literature review for the purpose of comparing results from the focus group discussions. A collection 35 papers were obtained from seven (7) research journals using three keywords i.e., ubiquitous computing, education and computer-mediated social interaction. Only "relevant" papers that were published from years 2008 to 2012 were extracted. The relevance of the papers was based on paper abstract content and keywords. The research journals where the papers were obtained are listed at ScienceWatch (ScienceWatch, 2012) and Celstec (Celstec, 2012) as some of the top ten (10) education journals or journals with the highest impact factor (IF). These journals are: American Education Research, Computers \& Education, Computers in Human Behaviour, International Journal of ComputerSupported Collaborative Learning, Journal of Educational Technology \& Society, Learning and Instruction, and Review of education research.

\section{RESULTS}

Results collected from the focus group interviews are presented in Table $1 \&$ Table 2. Some of the views expressed that appeared similar were grouped together. In general both ucomputing and computer-mediated social interactions were divergently perceived to be beneficial in learning and education by teachers and students. There are however drawbacks despite the numerous benefits revealed.

Table 1. SWOT of Ubiquitous Computing and Computer-mediated Social Interaction (Teachers' Views)

\section{Strengths}

- Mobility: anywhere "around"

- Convenience in terms of use

- Accessibility: 24/7 access anywhere

- Helps in getting organized and informed

- Faster communication (instant)

- Ability to overcome structural and time barriers

- Instant access and search for information, compared to "Mobile encyclopaedia"

- Collaboration is easier: peer-to-peer sharing of knowledge, asking and getting answers instantly

\section{Opportunities}

- New different and optional ways of interacting

- $\quad$ Student centered learning: taking teachers' role

- Democracy: Opportunity to overcome the disability of oppression

- Overcoming distance barriers

- Huge data storage capacity/knowledge repository

- Simple tools/applications e.g. e-books.

- Social pressure will overcome digital divide and externalities

- Based on constant changes, "There are very many unknown opportunities ahead which is an opportunity".

\section{Weaknesses}

- Digital literacy is required for example skills/knowledge on how to customize information and searches. "Getting much information leads to disorientation".

- Digital Divide (the skilled versus unskilled and the wealthy versus poor)

- Stress because of being connected all the time

- Noise in communication (diverting subjects or putting ideas out of context during information exchange)

- Technology failure and breakdowns

- Poor monitoring mechanisms, this allows students to cheat in assessments

\section{Threats}

- $\quad$ Privatization of application and social network sites used for learning: e.g. Facebook is going to charge for some applications: privatization leads to profit-centered thinking which is a threat to private information

- Digital divide

- Computer centered learning: too much reliance on computers

- Addiction to technology: too much time and space are consumed

- Privacy and security: "not knowing who is behind the machine", "visualization is important", viruses, hacking, authenticity etc.

- Individual socialization rather than group: there is a change in socialization dimensions from group to personal (talking to computers instead of people).

- Health hazards: back pain, radiation, stress, etc.

- Information Overload: too much information from (too many) different sources

- Externalities of digital tools: a non-priced cost or benefit that is incurred by a party who did not agree to the action causing the cost or benefit. 
- Technical dependence and faults: Poor infrastructure leading to poor coverage and connectivity

- Cost: relating to digital divide, etc.

Table 2. SWOT of Ubiquitous Computing and Computer-mediated Social Interaction (Students' Views)

- Strengths

- Time saving: "you can wake up later" if you have a task at hand

- Flexibility: self-paced learning

- Reporting is made easy for example communication of experiments

- Helps to develop knowledge of the internet and other computer skills

- Accommodates different learning styles

- Multitasking: allows doing many things at the same time

- Broad access (access from anywhere)

- Cost saving to learning materials (books, etc) and transportation to and from campus

- Provides easy networking platforms, discussion forums, etc.

- Storage: Permanent material storage allows re-use

- Availability of tools that enable making comments and contributions anytime

- Reduces dependent rates of students on teachers

- Tools for learners with special needs (assistive technologies)

\begin{tabular}{l}
\hline Opportunities \\
\hline $\begin{array}{l}\text { Studying and working at the same time is } \\
\text { possible }\end{array}$
\end{tabular}

- Affordability: So far the u-learning is cost effective and getting cheaper

- Collaborative environment and personalization

- Many requirements for example travelling documentation for overseas learners are overcome

- Cultural or political differences are overcome/ solved

- Getting technological skills

- Sharing ideas and interests with others and identifying community groups of shared interests

- Opportunities for disabled people

\section{Weaknesses}

- Bad study habits and learners' low motivation due to physical isolation from instructors and fellow students

- Lab work is difficult to simulate/ demonstrate in a virtual classroom

- Technical problems such as poor connectivity or low bandwidth internet for example in developing regions

- Delays in feedback affect the learner's participation: Instructors or fellow peers may not be available when students need help

- Learning/education software is complicated for beginners and may affect learners with low computer skills

- Disorientation: Getting confused or lost about course activities for example forgetting deadlines, paying less attention.

- Less confidence in teachers due to failure to manage class and indiscipline in virtual classrooms

- Affordability: Limited access to computers and other infrastructure needs such as electricity. Also, tuition fees and operational costs are at times high

- Time difference for distance learners causes inconveniences

- Noise in the environment (while learning from home, on the bus, everywhere)

- Lack of physical social activities with teacher and fellow students

\section{Threats}

- Health effects: Spending allot of time on a computer leads to exhaustion and stress

- Less human physical interactions: this affects social skills

- Creativity is also affected for example use of hand righting

- Creates unemployment, teachers are reduced in schools

- Plagiarism: copying from each other is inevitable especially from exchanged forum files and online tests. Exams can be attended by another student if cameras or biometric technology and agents/ invigilators are not used.

- Limited control for teachers. Some students become threatened (by other students) for example if other students dominate discussions. Even getting students back to classrooms after breaks is hard, discipline lacks

- Limited planning (less time is given to class preparations which leads to forgetting tasks)

- Noise and obstructions disorient learners

- Security and privacy such as access to personal profiles

\section{DISCUSSION}

In relation to existing literature, the results of this study presented above revealed some common understanding on the contributions and challenges of u-computing and computermediated social interactions in the areas of learning. Moos et al. (2009) shows that computerbased learning offers variety of functions that increase productivity of class work especially for students and their fellow intellectual partners. In relation to respondents' views, time saving due to efficiency was mentioned as a strength of u-computing and this factor yields to 
productivity, mentioned by Ibid. Related to productivity is Akkerman \& Bakker's overview of "boundaries". Like Shpigelman (2009), Akkerman \& Bakker (2011) indicate that computermediated learning helps learners to cross boundaries of space and time which solves some obstacles that would prevent learners from achieving their goals. They define "boundary crossing" as a person's transition and interaction across different sites, and "boundary objects" as artifacts helping in the crossing process, thus u-computing tools are boundary objects.

In Yang (2006), ubiquitous learning environment is said to provide "an interoperable, pervasive, and seamless learning architecture to connect, integrate, and share three major dimensions of learning resources: learning collaborators, learning contents, and learning services". These advantages featured in the interviews where both students and teachers mentioned how resources are networked together especially when it comes to collaboration and communication. Puustinen et al. (2011) reflects on this view by stating that, obtaining help among students when doing home works or reading is simple and possible for anyone equipped with technology. There are numerous online groups, forums, blogs, etc. that students can be part of to share knowledge and students are not driven by teachers but are rather selfregulated help-seekers. However these collaboration forums benefit self-motivated learners. Schoor \& Bannert (2011) confirms that, "collaborative learning leads to greater skills acquisition for less self-efficacious participants” (p. 561).

According to Liu \& Milrad (2010), the above instances of sharing and interacting with help of technology such as handheld devices breeds into new patterns of interaction and new classroom dynamics. Opportunities of one-to-one learning become inevitable. Liu et al. (2009) lists other u-computing opportunities such as (1) permanency (Learning is recorded and stored for re-use, (2) accessibility (full time access to learning information from any location), (3) Immediacy (information access and use of information at any time, (4) interactivity (learners are able to communicate with experts, teachers, peers, or machine), (5) situation (learners' context ware abilities using sensor network), (6) adaptability (learners' ability to get information anytime anywhere, (7) seamlessness (learners' ability to continue learning processes started elsewhere). The permanence factor does not only guarantee data surety but gives the opportunity to learners to critically reflect on their conversations and thinking at anytime (Wade et al., 2011). All in all Mills (2010) notes that, technologies like Web 2.0, which is part of u-computing, leverage distributed intelligence to all technology users even those with less expertise.

Besides the benefits of u-computing and computer-mediated social interactions mentioned above, literature shows that, there are challenges associated to the two concepts. These include: lack of motivation which leads to higher drop-out rates in online distance education courses as reported in Schoor \& Bannert (2011), reduced quality of access to socioeconomic marginalization of learners (Mills, 2010), difficulty to develop knowledge through these learning opportunities especially for students (Moos et al., 2009), anonymity of participants which leads to decreased self-awareness through deinviduation and could be a security threat (Ainsworth et al., 2011), less satisfaction and frustration due to limited skill and noise in communication and collaboration processes (Shpigelman, Weiss \& Reiter, 2009). All these challenges relate to the threats and weaknesses given during interviews presented in Table 1 \& Table 2. 


\section{SUGGESTIONS AND CONCLUSIONS}

This research has listed and discussed perceived strengths, weaknesses, opportunities and threats of u-computing and computer mediated social interactions as seen in the discussion section. Whereas there are various weaknesses and threats perceived, possibilities of eliminating them are also suggested in both interviews and literature.

We thus conclude with the remarks on computers by Newell \& Simon, and Turing that, "We can only see a short distance ahead, but we can see plenty there that needs to be done" (Newell \& Simon, 1976 p.126) and that, "although it is established that there are limitations to the powers of any particular machine, it has only been stated, without any sort of proof, that no such limitations apply to the human intellect" (Turing, 1950 p.445). We can say that u-computing offers more opportunities than threats and the threats can be overcome.

In a nutshell therefore, we suggest, among others, the following ways of overcoming threats and leveraging opportunities:

- Enforce policies for privacy and security

- Enforce control and prevention methods for cheating in exams and assessments

- Control anonymity when using online systems

- Prevent publishing or display of individual assessments. This breeds cheating.

- Minimize infrastructure interferences such as poor internet connections

- Reduce digital divide by promoting equal access

- Encourage methods for socialization among participants to bridge the virtual gap and make learning fun.

- Promote research that aims at providing affordable education using computers

In regard to the methodology of this study, we also suggest undertaking a similar study with a larger number of respondents.

\section{REFERENCES}

-Ainsworth, S., Gelmini-Hornsby, G., Threapleton, K., Crook, C., O’Malley, C \& Buda, M. (2011). Anonymity in classroom voting and debating. Learning and Instruction 21 (2011) 365-378

Akkerman, F., S. \& Bakker, A. (2011). Boundary Crossing and Boundary Objects. Review of Educational Research, 81(2), 132-169

-Camarinha-Matos, M., L. \& Anesh, A., H. (2005). Collaborative networks: a new scientific discipline. Journal of intelligent manufacturing, 16, 439-452

Celstec (2012). Advanced Learning Technologies Journal List. Accessed 28 April 2012 from: http://celstec.org/content/advanced-learning-technologies-journal-list

$>$ Chen, G. D., Chang, C. K., \& Wang, C. Y. (2008). Ubiquitous learning website: Scaffold learners by mobile devices with information-aware techniques. Computers \& Education, 50(1), 77-90.

-Chiou, C. K., Tseng Judy, C. R., Hwang, G. J., \& Heller, S. (2010). An adaptive navigation support system for conducting context-aware ubiquitous learning in museums. Computers \& Education, 55(2), 834-845.

-Feigenbaum, A., E. (1996). How the "What" Becomes the "How". Communications of the ACM, 39(5), 97-104

-Hsieh, S.-W., Jang, Y.-R., Hwang, G.-J., \& Chen, N.-S. (2011). Effects of teaching and learning styles on students' reflection levels for ubiquitous learning. Computers \& Education, 57(1), 1194-1201 
Huang, Y. M., Lin, Y. T., \& Cheng, S. C. (2010). Effectiveness of a mobile plant learning system in a science curriculum in Taiwanese elementary education. Computers \& Education, 54(1), 47-58.

Hwang, G. J., Shi, Y. R., \& Chu, H. C. (2010). A concept map approach to developing collaborative mindtools for context-aware ubiquitous learning. British Journal of EducationalTechnology 42 (5), 778-789

Jones, V., \& Jo, J. H. (2004). Ubiquitous learning environment: An adaptive teaching system using ubiquitous technology. In R. Atkinson, C. McBeath, D. Jonas-Dwyer, \& R. Phillips (Eds.), Proceedings of the 21st ASCILITE (Australasian Society for Computers in Learning in Tertiary Education) Conference (pp. 468e474). Perth, Australia: ASCILITE.

Liu, C., \& Milrad, M. (2010). Guest Editorial - One-to-One Learning in the Mobile and Ubiquitous Computing Age. Educational Technology \& Society, 13 (4), 1-3

Liu, T., Y., Tan, T., H. \& Chu, Y., L. (2009). Outdoor Natural Science Learning with an RFID-Supported Immersive Ubiquitous Learning Environment. Educational Technology \& Society, 12 (4), 161-175

Marshall, C; Rossman, G. B. (2006). Designing Qualitative Research. (4rth ed.) Thousand Oaks, CA: Sage Publications

-Martin, S., Diaz, G., Sancristobal, E., Gil, R., Castro, M., \& Peire, J. (2011). New technology trends in education: Seven years of forecasts and convergence. Computers \& Education, 57(3), 1893-1906

-Mills, A., K. (2010). A Review of the "Digital Turn" in the New Literacy Studies. Review of Educational Research, 80(2), 246-271

-Moos, C., D. \& Azevedo, R. (2009). Learning With Computer-Based Learning Environments: A Literature Review of Computer Self-Efficacy. Review of Educational Research, 79(2), 576-600

$\checkmark$ Newell, A. \& Simon, A., H. (1976). Computer Science as Empirical Inquiry: Symbols and Search. Communications of the ACM 19(3), 113-126

Peng, H., Chuang, P., Y., Hwang, G., J., Chu, H., C., Wu, T., T. \& Huang, S., X. (2009). Ubiquitous Performance-support System as Mindtool: A Case Study of Instructional Decision Making and Learning Assistant. Educational Technology \& Society, 12 (1), 107-120

-Puustinen, M., Bernicot, J. \& Bert-Erboul, A. (2011). Written computer-mediated requests for help by French-speaking students: An analysis of their forms and functions. Learning and Instruction 21 (2011) 281-289

Rabiee, F. (2004). Focus-group interview and data analysis. Proceedings of the Nutrition Society (2004), 63, 655-660

ScienceWatch (2012).Journals Ranked by Impact: Education \& Educational Research. Accessed 28 April 2012 from: http://sciencewatch.com/dr/sci/11/jan2-11_1/

-Schoor, C. \& Bannert, M. (2011). Motivation in a computer-supported collaborative learning scenario and its impact on learning activities and knowledge acquisition. Learning and Instruction 21 (2011) 560-573

-Shpigelman, C.-N., (Tamar) Weiss, P.L., Reiter S.(2009) E-Mentoring for All. Computers in Human Behavior, 25 (4), pp. 919-928.

Turing, M., A. (1950). Computing Machinery and Intelligence. Mind, New Series, 59(236), 433-460

Weiser, M. (1991) Scientific American, 265( 3) (1991), 94-104

Yang, S. J. H. (2006). Context Aware Ubiquitous Learning Environments for Peer-to-Peer Collaborative Learning. Educational Technology \& Society, 9 (1), 188-201 